\title{
FORMANDO FORMADORES: PROGRAMA DE PÓS- GRADUAÇÃO EM REDE NA ÁREA DE ENSINO
}

\author{
Ana Sara Castaman*, Ricardo Antonio Rodrigues \\ *E-mail: ana.castaman@sertao.ifrs.edu.br \\ Instituto Federal de Educação, Ciência e Tecnologia do Rio Grande do Sul - Campus Sertão \\ DOI: $10.15628 /$ rbept.2020.8520
}

Artigo submetido em abr/2019 e aceito em jan/2020

\begin{abstract}
RESUMO
O Programa de Pós-Graduação em Educação Profissional e Tecnológica (ProfEPT) representa uma oportunidade de reavaliar o Ensino em EPT. Assim, objetiva-se problematizar esta formação, a partir de uma abordagem qualitativa e por procedimento técnico bibliográfico, a partir: a) da formação dos formadores em EPT, por meio de provocações epistemológicas, antropológicas e filosóficas; b) da formação dos formadores no ProfEPT; c) da identidade e dos desafios no ProfEPT. Entende-se a partir destas problematizações que precisamos retomar o sentido do trabalho como princípio educativo, primando pela ação docente como condição da constituição da cidadania ativa, já que a missão em EPT é a formação omnilateral.
\end{abstract}

Palavras-Chave: Ensino. EPT. ProfEPT. Formação de formadores.

\section{TRAINING TRAINERS: POST-GRADUATE NETWORK PROGRAM IN THE TEACHING AREA}

\begin{abstract}
The Post-Graduate Program in Vocational and Technological Education (ProfEPT) represents an opportunity to re-evaluate the teaching in EPT. Thus, the objective is to problematize this formation, starting from a qualitative approach and by technical bibliographical procedure, starting from: a) the formation of the educators in EPT, through epistemological, anthropological and philosophical provocations; b) the training of trainers in ProfEPT; c) identity and challenges in ProfEPT. It is understood from these problematizations that we need to retake the meaning of work as an educational principle, emphasizing the teaching action as a condition of the constitution of active citizenship, since the mission in EFA is omnilateral formation
\end{abstract}

Keywords: Teaching. EPT. ProfEPT. Training of trainers. 


\section{INTRODUÇÃO}

As licenciaturas tendem a uma formação específica e fragmentada. Ao atuarem em Educação Profissional e Tecnológica (EPT), os licenciados necessitam realizar uma formação omnilateral e politécnica, bem como compreender o trabalho como princípio educativo. No entanto, com uma formação inicial notadamente positivista e cartesiana, as dificuldades acentuam. Os docentes em EPT, em sua maioria, carregam esta dupla lacuna, a de uma formação muito especializada e, portanto, específica demais, agregada ao fato de que a EPT exige um esforço relativamente grande de compreensão de todos os mecanismos e contextos que estão implicados em formar para a cidadania ativa. Acredita-se que enquanto não se der uma formação omnilateral em todas as etapas da educação, na licenciatura sequer haverá um encaminhamento para a ação de ensino na área específica, quanto mais para garantir uma atuação de natureza inter, trans e multidisciplinar da EPT.

Assim, além dos desafios com as questões do campo epistêmico, por conta da formação cartesiana, ainda há a necessidade de lidar com o papel político das ações empregadas. São trabalhadores que formam trabalhadores (MOURA, 2014), e não podem fugir dessa dimensão tão importante como as questões de fundo epistemológico e metodológico. O trabalho docente carrega em si uma dimensão política, a priori, ou seja, o conhecimento pode libertar e empoderar pessoas e comunidades ou simplesmente determinar papéis sociais, relegando a alguns protagonismos e a outros coadjuvância.

Esse sentido mais político da ação educativa, via de regra, também não é problematizado nas licenciaturas. Desse modo, a tendência natural dos docentes nas diferentes áreas, mesmo atuando em EPT, é de adesão ao conteudismo, de reprodução da ideia de meritocracia acadêmica, de reducionismo metodológico e da promoção de um ensino ou centrado no professor ou no conteúdo. Esta prática educativa não apenas deixa de promover a autonomia e autodeterminação nos/com os estudantes, mas as inviabiliza por completo.

Diante desse contexto, objetiva-se problematizar nesta produção textual acerca da formação dos formadores em EPT, refletindo em especial a partir do Programa de Pós-Graduação em Educação Profissional e Tecnológica (ProfEPT) em rede, área ensino, do Instituto Federal do Espírito Santo (IFES). Para tanto, a partir de uma abordagem qualitativa e delimitada por procedimentos técnicos bibliográficos, divide-se este artigo em três partes: a primeira aborda a formação de formação em EPT, a partir de provocações epistemológicas e metodológicas; a segunda reflete em específico sobre a formação dos formadores no ProfEPT, e, por fim, a terceira alude acerca da identidade e dos desafios no ProfEPT. 


\section{FORMAÇÃO DE FORMADORES EM EPT: PROVOCAÇÕES EPISTEMOLÓGICAS E METODOLÓGICAS}

A formação de formadores para a Educação Profissional e Tecnológica (EPT) comumente entrava em alguns desafios formativos per se, já que grande parte das licenciaturas em nosso país, de modo geral, constituem-se como bacharelados disfarçados que dificilmente problematizam de modo adequado a relação entre o saber sábio e o saber ensinado (CHEVALLARD, 1991). Pode-se enfatizar ainda que no processo formativo dos licenciandos no Brasil, a didática geralmente não é abordada com o enfoque e o aprofundamento necessário à formação, o que repercute em práticas de ensino, normalmente conteudistas e que confundem os meios com os fins. Entende-se que é mais importante a apropriação dos conteúdos específicos de cada área ou subárea do conhecimento - os saberes da formação profissional (TARDIF, 2002), do que o emprego destes enquanto ferramentas de empoderamento dos sujeitos.

Diante destas considerações, torna-se relevante realizar algumas provocações epistemológicas e metodológicas sobre a formação dos formadores. Acredita-se que para ensinar é imprescindível debruçar-se sobre o que é ensinar e o que consiste de fato, aprender. Quando não se pensa sobre as questões básicas do processo de ensino e aprendizagem, perpetuase o desconhecimento acerca dele.

A recusa da problematização de questões basilares do processo de ensino e aprendizagem, historicamente pode ter desencadeado certa carência formativa em história e filosofia da ciência e alguns pressupostos propedêuticos e epistemológicos sobre o significa fazer ciência, tecnologia e suas funções em todos os sentidos da vida humana. Essa ausência de reflexão quanto ao sentido e ao papel da ciência e da tecnologia, tornam os docentes reféns de correntes como o positivismo, o empirismo e o racionalismo, já que é mais confortável a adesão à uma corrente filosófica de pensamento do que questionar os seus limites e possibilidades conceituais (SAVIANI, 1989; 2007).

O estatuto epistêmico da ciência moderna, preponderantemente baseado no empirismo e no racionalismo, favoreceu uma visão mais simplista e linear sobre o mundo e as operações teórico-práticas da vida humana. Se por um lado, no empirismo temos a compreensão de que os fatos ou experiências, por si só, possibilitam uma visão real e correta do todo, disso decorre também a ingênua convicção teórico-prática que o método indutivo dá conta de nossos desafios em todos os campos. De modo mais reducionista, o empirismo habilita a crer que os fatos particulares podem indicar acuradamente a compreensão do todo. Algo combatido por Popper (1972) ao inferir que ao avistar uma garça de determinada cor, não se pode 
achar que se tem elementos suficientes para crer que todas as garças são ou serão assim.

Por outro lado, no modelo epistêmico racionalista tende-se ao inverso, visto que se tem a propensão de pensar que o internalismo conceitual, a compreensão racional de conceitos e as entidades abstratas, por si só permite além da abstração das ideias claras e distintas, compreender e explicar todos os fenômenos e entes particulares a partir delas. Na visão de Descartes (1996), o esclarecimento, resultado do esforço puramente racional, conteria a verdade indubitável.

Sabe-se que o paradigma moderno foi e é de suma importância na superação do obscurantismo que impediu, de certo modo, o progresso científico e tecnológico. Porém, o antropocentrismo decorrente da modernidade, mediou uma ideia de que o mundo poderia e deveria ser dominado e transformado de acordo com as convicções, necessidades e intenções do indivíduo.

Essa virada conceitual da autonomia filosófica e do uso da capacidade humana para transformação da realidade vivida, serviu de base conceitual para alavancar uma mudança teórico-prática na relação do homem com os seus pares e também com a natureza. Aponta-se a consciência humana como oportunidade de modificação da realidade em todos os sentidos e a constituição de um antropocentrismo que aos poucos foi gerando uma inquisição medieval ao inverso, porque sedimentou a visão de que fora dos parâmetros do racionalismo e do empirismo, não é possível pensar nenhum tipo de possibilidade teórico-prática. Saber é poder, logo ensinar ciência e tecnologia implica em produzir saberes e fazeres que ampliem o bem-estar do humano, como bem sugeriu Bacon (1973).

Conforme Burguete (2004), construir uma história e uma filosofia da ciência é condição para, efetivamente, fazer-se ciência. Segundo o autor, é necessário situar em um contexto maior o que significa aquilo que está sendo ensinado, partindo-se de um entendimento do que levou aquele saber a se constituir em seu contexto originário, a sua atribuição e o seu sentido no tempo. Implica em ter autonomia e consciência.

O paradigma filosófico e científico moderno deu ao ser humano importantes elementos para a constituição de sua autonomia e consciência. É fundamental que a relação estabelecida com esses pressupostos teóricos modernos seja crítica e autocrítica, não apenas de uma atitude de adesão e repetição de seus pensares e fazeres. Logo, enquanto docentes de instituições que pensam a ciência e a tecnologia, não se pode furtar das observações de Morin (2014) ao reclamar que para quem faz ciência como para quem a ensina, falta uma consciência sobre os limites e as possibilidades da própria ciência. A ciência enquanto produção humana (CHALMERS, 1994; 1995) deve ser refletida, revista, ressignificada, atualizada e reavaliada sempre. Isso também vale para a tecnologia. 
O grande desafio conceitual para os Institutos Federais de Educação, Ciência e Tecnologia (IF) é perceber que se leva centenas de anos para constituir a ciência e a tecnologia como condição de possibilidade para a autonomia e a consciência. Mas, no contexto atual, ambas estão preponderantemente a serviço do mercado e da produção de saberes que empoderam alguns e subjugam a maioria relegando-os apenas a condição de consumidores.

A democratização do saber (SAVIANI, 2007) passa por uma história e filosofia da ciência e uma problematização epistemológica (MORIN, 2007a; 2007b; 2014) sobre as bases conceituais que orientam e fundamentam todos os processos de compreensão, explicação e evolução da ciência e da tecnologia (BURGUETE, 2004). Ao conceber-se um mestrado profissional em ensino, na área de concentração da Educação Profissional e Tecnológica, deve-se pensar nas amarrações que podem despontar e nas possibilidades teórico-práticas descobertas, uma vez que as instituições federais precisam pensar e fazer acontecer a formação omnilateral para a convicção do trabalho como princípio educativo.

A ausência de um trabalho profícuo de epistemologia, história e filosofia da ciência, pensado à luz da didática, somada à falta de investigação sobre as bases conceituais dos diferentes saberes, impossibilita que o docente seja capaz de autodeterminar-se, de escolher entre os vários caminhos e perspectivas de ensinar. Por conseguinte, esse profissional corre o risco de cair num triplo mecanicismo (separação entre theoria e práxis; separação entre saber sábio e saber ensinado; desconexão substancial entre os diferentes saberes) que aos poucos vai esmaecendo o sentido da ensinagem (ANASTASIOU, 2007) nos complexos e múltiplos processos de ensino e aprendizagem. A dificuldade de compreensão da ciência como produção humana e de todos os seus elementos fundantes, coloca o professor na posição de mero reprodutor de conteúdos e informações não conectadas à realidade vivida pelo estudante e tampouco intimamente atreladas ao seu sentido mais profundo de promoção de autonomia e autodeterminação pelo saber.

Kuhn (1997) alerta para o paradigma de que sempre ensina-se e fazse ciência de um lugar. No entanto, a grande maioria dos formadores ainda está imerso no paradigma cartesiano, sem ter consciência do significado dele. Se não perceberem ou reconhecerem o horizonte teórico ao qual se encontram inseridos, não há possibilidades de buscar alternativas para o mesmo, bem como a constituição de uma visão inter, multi e transdisciplinar. Não faz sentido pensar um currículo integrado, em nível de Stricto Sensu, se não se compreender a necessidade de superar o cartesianismo à luz de um novo paradigma.

Ao pensar as teorias e práticas em EPT, a primeira cena que impacta é a convicção de que os docentes derivam de uma experiência pedagógica formativa e profissional em que predomina o pensamento cartesiano, 
empirista e positivista. Essa formação disciplinar e reducionista é tão específica que naturalmente pode se tornar avessa ao inter, multi e transdisciplinar. Ainda que se tenha um bom projeto pedagógico de curso, em si, não convence os docentes às práticas efetivamente integradas e integralizadoras dos saberes e fazeres (FRIGOTTO; CIAVATTA; RAMOS, 2005; FRIGOTTO, 2009).

Os Projetos Pedagógicos de Curso normalmente são construídos de maneira cartesiana, sendo relegado aos 'especialistas' de determinada área de conhecimento a missão de elaborar esta proposta, desconsiderando a participação dos demais docentes. Assim, como não participaram de toda a concepção e elaboração, não conseguem ter uma visão do todo e tampouco conectar os saberes e fazeres (MORIN, 2007a; 2007b).

Mesmo em cursos integrados, a prática mais comum de escrita dos Projetos Pedagógicos de Curso é a constituição cartesiana, desvinculada e desconexa entre as diferentes áreas e saberes, o que promove a perpetuação da fragmentação na prática pedagógica. A ideia de integração que faria frente a esse modelo disciplinar, pode e deve promover o encontro entre os saberes. Destarte, para que isso aconteça de fato, é necessário revisar os fundamentos e práticas em torno deste nível de ensino (SAVIANI, 1989; FRIGOTTO; CIAVATTA; RAMOS, 2005; MOLL, 2010).

O desafio para a constituição de um trabalho inter, trans e multidisciplinar nos IF começa no entrave da própria formação docente e da ideologia impingida pelo mercado e pela universidade, como extensão deste. A educação ainda está refém de um modelo em que o capital determina às universidades suas demandas e anseios. No caso dos IF, é preciso superar o modelo cartesiano de ensinar e aprender, do positivismo que hierarquiza saberes, oriundo da formação 'bacharelesca' das licenciaturas para conseguir lidar com suas bases conceituais.

As licenciaturas ainda não conseguem promover a formação de uma visão sistêmica em seus egressos. A própria compreensão da ciência como processo de construção permanente fica comprometida na medida em que fazer ciência é diferente de ensinar ciência. Lamentavelmente, a problematização entre o saber sábio e o saber sabido (CHEVALLARD,1991) é comumente negligenciada na ligação e religação dos saberes nos cursos de licenciaturas.

Grande parte dos docentes em EPT foram formados numa perspectiva disciplinar e específica, que possui muito mais o caráter de um bacharelado disfarçado do que propriamente uma licenciatura de fato. Essa fragmentação do saber dentro da própria área do conhecimento, cartesiana em sua constituição teórica e prática, culmina num processo formativo que faz o docente adotar um modelo de ensinar e aprender que prime pela especialização, pela especialidade de sua área de conhecimento e não raramente por pensar que os demais saberes são inferiores ou de menor 
importância. Esse é um resultado notadamente positivista do processo formativo, pois para Comte (1936) existem saberes que são importantes e outros não.

Logo, a tendência natural é a de que o docente reproduza, em grande parte, os saberes docentes e a formação profissional que constituem a sua identidade pessoal e profissional. Raros são os espaços em EPT que efetivamente enfatizam e valorizam as experiências pedagógicas, científicas e metodológicas do ponto de vista teórico-prático, que priorizam as bases conceituais dos diferentes saberes, problematizam seus conteúdos à luz da teoria do conhecimento e praticam a reflexão gradativa e sistemática sobre seus processos de ensino e aprendizagem. Falta uma consciência da relevância da própria consciência (MORIN, 2014).

Assim como a ciência não possui consciência da própria consciência que deveria ter sobre seu sentido e papel (MORIN, 2014), os sujeitos que a constituem, bem como a seus processos, não a problematizam suficientemente dentro da perspectiva mais crítica e basilar. Nem se preocupam 0 bastante com a necessidade formar cidadãos planetários (MORIN, 2007a).

Ao se tratar de EPT, pela sua própria natureza, é essencial combinar ciência e tecnologia numa perspectiva que resista à tentação da linearização e da simplificação epistemológica. Quando não se observa a complexidade implicada em todo e qualquer processo educativo e de reflexão sobre a constituição da ciência e da tecnologia, simplesmente perpetua-se saberes e fazeres que não promovem a cidadania ativa e o efetivo progresso do conhecimento humano.

Destarte, formar formadores a partir da proposta da EPT é instigar os docentes a perceberem de que esta é e deve ser permanente/continuada. Nenhuma graduação e/ou Pós-Graduação forma definitivamente alguém. A ideia de que o conhecimento é sempre desconhecer e querer conhecer (SANTOS, 2008) garante minimamente ao docente uma atitude de autodeterminação e revisão permanente do saber e das condições que permitem o conhecimento, seus limites, possibilidades e implicações.

O docente que se propõe a trabalhar com EPT precisa ter clareza da sua formação incipiente (no sentido freireano do inacabamento), ter interesse e desejo de superar a (de)formação científica, pedagógica e tecnológica que recebeu e buscar meios para superar a fragmentação da realidade e dos saberes. Raras são as licenciaturas que formam para atuar em EPT, esse é um ofício que exige do sujeito uma disposição a aprender e praticar cotidianamente seus princípios/fundamentos.

Ensinar na área de EPT exige uma postura crítica diante da realidade, consciência do papel político da ação educativa e da necessidade de uma base epistemológica mínima, como condição de possibilidade para fazer do trabalho um projeto de produção de saberes e não apenas de 
reprodução inconsciente de fazeres (SAVIANI, 1989). O movimento teórico de levar o futuro docente a fazer a experiência socrática do "só sei que nada sei", é um importante caminho para que o professor possa colocar-se na condição de aprendiz, com a disposição de aprender a aprender (ASSMANN, 1998) para poder ensinar. Além disso, implica em não somente "[...] qualificar para o mercado, mas para a vida" (AGUIAR; PACHECO, 2017, p.14).

A reflexão sobre a prática docente em EPT, faz-se necessário para a partir disso (re)formar os professores em serviço, não no sentido de desprezo aos saberes até então produzidos, mas considerar que a formação disciplinar específica, passa indispensavelmente por um processo de profunda revisão rumo ao saber inter, multi e transdisciplinar. $\mathrm{Na}$ Carta da Transdisciplinaridade (MORIN; FREITAS; NICOLESCU, 1994) encontra-se substratos e indicativos sobre os caminhos a serem seguidos numa nova perspectiva paradigmática.

Diante disso, é preciso de concepções teórico-práticas que possibilitem a migração de um modelo convencional de ensino (refém dos ditames do mercado) e fomentem uma profunda reflexão sobre o ensino em EPT. Necessita-se superar a visão arcaica de que educação profissional é sinônimo de formação de mão de obra barata, relegando o papel do ensino à uma mera repetição de informações ou saberes que não oportunizam ao estudante ter condições teórico-práticas de transformar a sua vida e a realidade em que vive. Ensinar em EPT é romper interditos e não reproduzir a exclusão.

O trabalho docente em EPT precisa ser desalienado e desalienante para conseguir produzir no estudante um movimento mínimo e gradativo de consciência. Do mesmo modo, sem a compreensão mínima do professor sobre todos os mecanismos de poder e controle que existem na vida social, não se oportuniza ao estudante uma visão mais crítica e criativa sobre a realidade. A consciência do professor é condição fundamental para o despertar a do estudante (MORIN, 2014).

$\mathrm{Na}$ esteira do que sugeriu Morin (2014) a respeito da consciência de quem faz ciência, produzir saberes em EPT requer uma visão abrangente ao mesmo tempo meticulosa e cuidadosa, articulada e sistêmica - sobre as nuances implicadas no processo de ensino que pretende formar os trabalhadores do futuro, num contexto de globalização econômica, meio político difuso e cultural polissêmico (OLIVEIRA, 2003; 2007; SAVIANI, 2007). Não se tem a obrigação de apenas atender ao mercado, oportunizando ao bel prazer do capital uma formação rápida e rasa para os novos trabalhadores. Precisa-se promover a inadiável reflexão acerca dos sentidos do trabalho (ANTUNES, 1999) e a devida clareza que o docente é também um trabalhador, o qual precisa praticar a reflexão sobre o sentido, a natureza e 0 papel da ação enquanto tal (MOURA, 2014). 
Nesse sentido, é de suma importância que o docente entenda o papel da reflexão enquanto uma alternativa para melhorar o seu próprio trabalho. Para tanto, na sequência, para ampliar a discussão em torno do tema da docência em EPT, versa-se sobre a formação de formadores que atuam no Programa de Pós-Graduação em Educação Profissional e Tecnológica (ProfEPT).

\section{FORMAÇÃO DE FORMADORES NO ProfEPT}

A formação dos formadores em EPT é "[...] a formação omnilateral da pessoa, unindo ensino, pesquisa e extensão" (AGUIAR; PACHECO, 2017, p. 14). Não se pode pensar o ensino em EPT dentro de uma lógica monocrática das universidades em geral. É comum nos processos formativos universitários que a extensão aconteça quando for possível, que a pesquisa, sobretudo a aplicada, seja o carro chefe de algumas áreas e a pesquisa básica, esteja de algum modo, atenta aos interesses do mercado. Normalmente o ensino ocupa a maior parte do tempo do processo formativo dos discentes.

Assim, geralmente, em instituição de ensino superior, a articulação entre ensino, pesquisa e extensão é notadamente cartesiana, empirista e positivista. Já nos IF, pela sua natureza e base conceitual de fundação, a relação entre o ensino, pesquisa e extensão deve ser pensada e praticada de modo diverso daquele modelo convencional das universidades. Muito embora, por causa da formação dos docentes e de seu enraizamento no universo da pesquisa universitária, o que ainda se pratica nos IF, em termos dessa tríade é a perpetuação do modelo monocrático hierarquizado, linear, das universidades.

Ao refletir sobre o sentido originário do trabalho e seus múltiplos significados, a importância da ciência e da tecnologia, seus impactos na vida humana, percebe-se facilmente que a identidade dos IF deve conduzir à uma outra forma de pensar e de ser, conjugando acesso, permanência e êxito, conhecimento e consciência, inclusão e autonomia, diversidade e liberdade, coadunando o saber e o fazer na perspectiva de produzir novos fazeres e despertar novos saberes. Desse modo, a extensão nos IF tem um papel de importância distinto da universidade que faz extensão quando é possível. Naqueles, a extensão é a condição de possibilidade para uma pesquisa que promova o desenvolvimento regional efetivo, e o ensino será movido pelas demandas da pesquisa e extensão como modo privilegiado de reinventar-se sempre, visando a promoção e o desenvolvimento local.

A considerável diferença é que as universidades ainda carregam o estigma do projeto pessoal de distinção social, enquanto os IF, em sua natureza mais fundamental, a convicção de que o saber deve ser colocado a 
serviço das pessoas e da ampla sustentabilidade. Essa clareza, dificilmente os docentes em EPT possuem na hora de prestar um concurso para tal, o que vai sendo descoberto e elaborado aos poucos. Ao formar investigadores para pensar sua identidade, remonta-se o sentido originário dos IF, que como já dito, possuem o protagonismo e a prerrogativa para a inclusão e promoção social e como princípio e fim de sua ação educativa, promover as pessoas e o desenvolvimento local.

Diante deste escopo, a formação continuada faz-se necessária. Para tanto, propostas de Mestrados Profissionais em EPT têm sido apresentadas como uma opção para atender esta demanda e cumprir com o princípio da verticalização do ensino. Assim, em 16 de setembro de 2016, foi criado pela Resolução do Conselho Superior n161, o Programa de Pós-Graduação em Educação Profissional e Tecnológica, pelo Instituto Federal de Educação, Ciência e Tecnologia do Espírito Santo (IFES).

Este programa, concebido pelo Conselho Nacional das Instituições da Rede Federal de Educação Profissional, Científica e Tecnológica (CONIF), está sendo oferecido no IFES - Campus Vitória e em mais 35 polos de instituições associadas. O programa teve sua primeira oferta de ingresso no ano de 2017, com mais de 26 mil inscritos para as 420 vagas ofertadas. Regidos pelo Edital 01/2017, teve o processo de constituição das primeiras turmas nos 18 polos. O Edital 02/20107 balizou o processo seletivo das 20 vagas para a turma especial do Ministério da Educação (MEC). Em 2018, o edital 01/2018 orientou o processo seletivo para as 820 vagas, o número de docentes credenciados também dobrou, assim como o número de instituições associadas que eram 18 e agora são 36.

O ProfEPT tem por finalidade formar em serviço profissionais capazes de elaborar e desenvolver pesquisas atreladas ao ensino, de espaços formais e não formais de educação em EPT; produzir conhecimento por meio de produtos que integrem os saberes peculiares ao mundo do trabalho. Para dar conta desta proposta a Coordenação do Programa organiza Seminários de Alinhamento Conceitual, os quais ocorrem de forma semestral.

Essa iniciativa concreta de pensar e oportunizar por meio de novos saberes e fazeres, faz do ProfEPT uma ação privilegiada de constituição ampla e plena da própria Rede Federal de Ensino Técnico e Tecnológico. O ProfEPT inevitavelmente reinventa a relação entre ensino, pesquisa e extensão que via de regra, ainda reproduzem o modelo monolítico das universidades.

Esse espaço de retomada de conceitos e preceitos no ensino, na pesquisa e na extensão, permitem aos IF 0 autoconhecimento e 0 reconhecimento do seu papel social e cultural na sociedade brasileira. Considerando que as universidades, de modo geral, resistem em formar os novos licenciados dentro de uma lógica inter, multi e transdisciplinar, cabe 
aos IF assumir essa transição e esse processo formativo mais ousado e ao mesmo tempo necessário para aqueles docentes que pretendem trabalhar com EPT.

Nesse sentido, o próprio ProfEPT vai aos poucos configurando a possibilidade de um processo de formação permanente dos docentes que trabalham ou podem vir a atuar em EPT, refundando o seu próprio processo formativo, atualizando sua identidade e oportunizando novas perspectivas de saberes e fazeres pedagógicos que atendam a natureza complexa de um ensino contextualizado, crítico e criativo. Formar formadores significa repensar e reavaliar constantemente o processo formativo, no sentido de aperfeiçoá-lo.

Desse modo, o ProfEPT pode oportunizar uma profunda reflexão sobre a identidade da Rede Federal, incitando um novo entendimento acerca do ensino e sua articulação com a pesquisa, a interação e a relação mais contundente entre a extensão e o próprio ensino ligando essas dimensões à função insubstituível da pesquisa. Os IF não podem se conformar ou se identificar com a condição social de muitas universidades que privilegiam 0 projeto pessoal do estudante ou do pesquisador em detrimento do reconhecimento e da promoção dos sujeitos coletivos.

Os IF existem para propagar o conhecimento e promover o desenvolvimento local, não para se tornarem novas formas universitárias de reprodução de saberes e fazeres que não chegam a todos de modo sistemático, crítico, criativo e transformador. Ao instituir um mestrado profissional em rede, tem-se a possibilidade de rever todo o processo formativo, as demandas teórico-práticas, bem como refletir sobre a dimensão social, política, cultural e econômica dos IF na transformação ampla e plena que oportunize o desenvolvimento omnilateral da cidadania ativa e da constituição de uma sociedade livre e democrática.

As demandas fomentadas pelo ProfEPT poderão difundir no processo educativo dos IF uma reflexão sobre as nossas limitações formativas permitindo um olhar autocrítico para o tipo de relação que o professor estabelece com o conhecimento, os sujeitos aprendentes e os demais saberes. Essa dupla competência que Nóvoa (2011) sugeriu em seus textos, do professor que domina profissionalmente os saberes de sua alçada, mas também procura (re)conhecer os limites e possibilidades dos sujeitos que estão envolvidos no processo de aprender (SAVIANI, 1989; 2007).

Deste modo, a reflexão sobre as reais necessidades, lacunas e demandas formativas permite de igual modo, conhecer as bases conceituais envolvidas na EPT. Para tanto, o ProfEPT preocupa-se em apresentar a noção de trabalho como princípio educativo (FRIGOTTO, 2005; 2009), uma revisão sobre o que se entende e pratica em termos de tecnologia e ciência, sem perder de vista o horizonte do papel do ensino e de como ele necessita ser pensado e praticado. Diante do papel do curso e de sua concretização em 
rede, busca-se problematizar a identidade e os desafios deste programa em rede.

\section{O PROFEPT - IDENTIDADE E DESAFIOS}

Sabe-se que o ProfEPT ampliou seu nicho e definiu especificidades, com a finalidade de otimizar a formação continuada, a produção de conhecimento e a qualificação dos profissionais para o mercado brasileiro. Barros, Valentin e Melo (2005) marcam que os programas de mestrado profissional devem estar pautados no rigor do desenvolvimento da pósgraduação stricto sensu, balizados por um projeto pedagógico, além de por conhecimentos e habilidades enlaçados à prática profissional e ao avanço tecnológico. Destarte, ao tratar de programas de pós-graduação em rede como o ProfEPT, para além destas características, implica no alinhamento conceitual e de práticas.

Para a concretização do alinhamento conceitual e de práticas, o ProfEPT, organiza Seminários, destinados aos seus coordenadores e professores. Os docentes participaram de formação com discussões acerca do curso (apresentação, base conceitual, plataforma) e dos temas: Trabalho e Formação Docente na Educação Profissional; Produtos da pesquisa em ensino: cenário atual, desafios e perspectivas; Avaliação de Programa de pós-graduação na área de Ensino; Preenchimento do Currículo Lattes. Em outras capacitações versou acerca das seguintes temáticas: Trabalho e Formação Profissional na Educação Profissional e Tecnológica; Produtos da pesquisa em ensino: cenário atual, desafios e perspectivas; Perspectivas de Pesquisas; Avaliação de Programa de pós-graduação na área de Ensino; Metodologias de Ensino: possibilidades e relações com o Mestrado Profissional na Área de Ensino.

A concretização da rede federal de ensino que possui em sua natureza a missão da formação omnilateral se efetivará, de fato, quando os docentes envolvidos nesse processo compreenderem minimamente que 0 trabalho docente exige uma consciência sobre a necessidade de uma consciência (MORIN, 2014) para ensinar ciência e tecnologia, produzir novos saberes e fazeres, bem como retomar o entendimento originário do trabalho enquanto princípio educativo, não apenas como produção de mão-de-obra especializada. Como aponta Antunes (1999), há uma polissemia nos sentidos e papéis do trabalho em nosso tempo. Não há porque repetir os modelos fordistas, tayloristas ou mesmo toyotistas nas instituições de ensino, formando e (in)formando as novas gerações apenas para os desígnios do mercado capitalista (MOLL, 2010).

O papel formativo contínuo e a convicção do trabalho como princípio educativo deve ser pauta constante nos meios acadêmicos para romper com 
o dualismo histórico, tanto da formação especializada em detrimento da formação omnilateral, como da cisão entre teoria e prática, as demandas do mercado e a realidade vivida. O alinhamento conceitual não se faz necessário apenas para trabalhar os mesmos textos e autores, metodologias e estratégias semelhantes em todos os polos. Demanda-se constituir uma convicção sobre o papel de formadores de cidadãos críticos, criativos e conscientes de sua condição humana, da própria dignidade humana e da demanda inadiável de formar formadores com um compromisso de oportunizar às novas gerações condições de empoderamento, senso crítico para a leitura e transformação do meio em que vivem.

Precisa-se superar também a dicotomia milenar do trabalho como expropriação do ser, tortura ou modo de permitir a exploração de uns sobre os outros. Ao retomar o sentido e o papel do trabalho como princípio educativo Gramsci (1978; 1982) o faz em função de combater a ideia que legitimava dois tipos de formação escolar em seu tempo. A escola para ricos e a para pobres, sendo que no primeiro caso havia uma ênfase na formação integral e no segundo uma formação mais instrumental.

As tendências de reforma no ensino básico, atualmente, parecem apontar para um processo de celeridade na formação de trabalhadores, subtraindo-os o entendimento de todas as nuances e armadilhas deste processo. Moura (2014) alerta que para fazer um trabalho formativo adequado à realidade da EPT, remete que os educadores se descubram enquanto trabalhadores. Dito de outro modo, são trabalhadores formando e intervindo no processo formativo dos novos trabalhadores. Nisso está a urgente necessidade de ressignificar o trabalho docente enquanto condição de possibilidade da autoformação crítica e cidadã dos educadores.

$\mathrm{Na}$ perspectiva de Gramsci (1978; 1982) e Marx (1982) a problematização do tema do trabalho, e porque não dizer do próprio trabalho docente, deve ser sempre um esforço teórico-prático de não apenas ler a realidade, como bem apontava Freire $(1987 ; 2002)$, mas buscar de todas as formas a sua transformação. As relações de poder no entendimento teórico e na constituição prática do trabalho contemporâneo ainda carregam resquícios daquilo que Hegel (1974) propôs em sua Fenomenologia do Espírito, sugerindo que a tensão entre o Senhor e o Escravo eram movimentos necessários para a evolução da história e da cultura humana.

Os docentes da EPT, não podem e nem devem compreender o ofício como mera interpretação dos múltiplos mecanismos de exploração e desumanização no mundo do trabalho. A parte mais nevrálgica da função docente está imbuída na transformação dessas relações opressoras, injustas, mecânicas, lineares, que tendem a colocar o ser humano como meio e não fim de todos os processos. A luz de Freire (2002), pode-se inferir que o fazer docente deve ser de transformação, a partir de um pensar que interpreta a realidade e suas contradições. A práxis precisa estar alinhada ao sentido do 
trabalho enquanto princípio educativo e não uma dialética necessária entre o senhor e o escravo, conforme sugeriu Hegel (1974).

Os lampejos de esperança que se acendem na incipiente caminhada do ProfEPT é justamente esse movimento de (re)configuração da teia que une instituições que lidam no cotidiano com os desafios teórico-práticos do ensino em EPT. Ao tomar-se como base os três seminários de alinhamento realizados respectivamente em São Paulo, Curitiba e Fortaleza e o IV Seminário de Alinhamento em Goiânia, em 2018, nota-se que, atualmente, cerca de 200 docentes com doutorado - em torno de 252 estão sendo cadastrados -, em todo o território nacional, estão dispostos a pensar suas atuações em EPT. Esse movimento dos mais de 200 doutores, que trabalham nos diferentes níveis de ensino da EPT, em todo o território nacional - apenas dois estados ainda não estão contemplados pelo ProfEPT-, indica um caminho novo de boas perspectivas. É um possível ponto de partida para refletir de modo sistemático e crítico sobre a realidade, identidade e papel social dos IF.

Se somar os esforços de centenas de docentes distribuídos nos 36 polos, em processo de formação permanente sobre o trabalho docente e a perspectiva do trabalho em nosso tempo, com os do significativo número de mais de 30 mil candidatos que pleitearam as 820 vagas oferecidas para o curso no país todo, vislumbra-se um cenário muito promissor. Inaugura-se uma fase de pensar e fazer a prática educativa, aprofundando as bases conceituais da EPT e ampliando os debates à comunidade em geral, tendo em vista que foram oferecidas e serão ocupadas mais de 400 vagas, por cidadãos que buscaram uma vaga no curso via ampla concorrência.

Esses são os primeiros passos de um Programa de Pós-graduação que imprime um modo de ser e estar nas diferentes unidades dos IF. Também os são do docente que ao escolher o ProfEPT para ministrar aulas e orientar estudantes, em nível de Stricto Sensu, estará assumindo um múltiplo desafio de retomar a identidade conceitual dos IF, alinhar seus conhecimentos aos de seus pares que irão ministrar as mesmas disciplinas nos 36 polos, além de constituir um grupo sólido de pesquisa como modo de enfrentamento local aos problemas de ordem teórico-práticos da EPT. São formas de superar o cartesianismo, o empirismo, o positivismo impregnado em suas trajetórias formativas para galgar passos rumo à uma autoformação omnilateral e permanente capaz de romper com os ditames de um sistema educacional travado pelo mecanicismo cartesiano e pela idolatria do positivismo.

Além do alinhamento com a visão de politecnia, formação omnilateral, enfim, da compreensão fundamental do trabalho como princípio educativo, é necessário um salto rumo à prática docente de cunho inter, trans e multidisciplinar, decorrente de pressupostos epistemológicos que possam ajudar a superação do paradigma dominante (SANTOS, 2008). Se ao longo de alguns anos, os resultados não forem de uma expressiva superação das 
dificuldades teórico-práticas do ensino na EPT para refletir e agir na direção da garantia desse processo como modo privilegiado de educação, capaz de formar as novas gerações em uma perspectiva integral e integradora dos saberes e fazeres, ao menos centenas ou milhares de discentes formados e formandos do ProfEPT terão tido a oportunidade, jamais tida e vista antes, de reflexão, debate, produção de incontáveis seminários e textos. Estas ações fomentarão de modo irreversível uma possibilidade de transformação teóricoprática do ensino em EPT, pelas questões acadêmicas inerentes ao processo formativo dos docentes, preparação e envolvimento no Exame Nacional de Acesso (ENA), e de forma especial, no gradativo envolvimento dos docentes e discentes na concretização dos denominados produtos pedagógicos.

\section{CONSIDERAÇÕES FINAIS}

Os Institutos Federais são resultado de uma concepção de ensino que pretende enfrentar desafios teórico-práticos na área de EPT. No entanto, esse trabalho exige constante vigilância e reavaliação de todos os processos pelos envolvidos. É a consciência da necessidade de uma consciência, como bem sugeriu Morin (2014), tanto para quem produz ciência como quem a ensina, um entendimento de que não há como fazer ciência efetivamente sem compreendê-la como produto e fabricação humana (CHALMERS, 1994;1995).

Os IF carregam em seu nome as insígnias da ciência e da tecnologia, quase sempre concebidas de forma ingênuas ou com fundamentos pretensiosos, sem considerar todas as nuances presentes na história e na filosofia da ciência (BURGUETE, 2004). De acordo com Arendt (2005), a reflexão consistente é o único caminho para resistir aos mais diferentes modos e formas de totalitarismos. Pensar sobre os fundamentos epistemológicos em que estão fundados os pressupostos modernos e contemporâneos do ensino, da ciência, da tecnologia, conforme orienta Morin $(2007 ; 2014)$ e da cultura como um todo, permite problematizar todos os processos e ações em EPT de forma mais precisa, do ponto de vista teóricoprático.

A reflexão sobre o impacto do cartesianismo, do empirismo e do positivismo nos processos de ensino e aprendizagem, bem como sobre a necessidade de que o trabalho seja compreendido e praticado como princípio educativo e não como forma de exploração, indicam um futuro promissor. $O$ trabalho, a ciência e a tecnologia precisam ter suas definições e conceitos aprofundados e retomados. Não convém uma visão do trabalho apenas no horizonte taylorista, fordista e toyotista (ANTUNES, 1999), uma vez que conceitualmente a realidade já imprimiu esses modelos em crise, tendo em vista que a riqueza das nações ou de alguns não pode ser constituída com o trabalho como modo de expropriação do humano. A visão do trabalho com 
seu sentido sisífico, como um duplo castigo (mental e físico), necessita ser retomada de modo mais intenso, considerando que se atua em educação e forma-se os trabalhadores do futuro.

O trabalho como princípio educativo deve ser a bandeira de luta e para tal, precisa-se reivindicar uma formação cidadã e omnilateral, que preze e fortifique a inteireza do ser humano. Educar e ensinar em EPT é retomar os fundamentos que a regem, é um modo de reafirmar a consciência dos sujeitos em torno dos seus processos em todos os campos. É identificar, reconhecer e minimizar os mecanismos de opressão e de descaracterização do humano.

Nesse sentido, o ProfEPT pode, a partir de um olhar mais cuidadoso sobre as bases conceituais da EPT que o fundamentam, renovar o compromisso que tem na produção de saberes e fazeres comprometidos com uma formação omnilateral, com o entendimento do trabalho como princípio educativo (GRAMSCI, 1978, 1982; FRIGOTTO; RAMOS; CIAVATTA, 2005), por meio de uma visão crítica do professor como trabalhador que forma trabalhadores (MOURA, 2014). O trabalho é acima de tudo potencial de vida e não pode ser visto apenas como um mal necessário ou modo de expropriar dos trabalhadores sua dignidade, colocando-os como meros instrumentos a serviço do capital (MARX, 1982).

O ProfEPT é um espaço privilegiado de concretização da Rede Federal no sentido teórico que oportuniza uma revisão de suas bases conceituais, assumindo-as efetivamente como ferramenta de transformação humana e social, não apenas como estratégia de interpretação da realidade. $O$ mero diagnóstico sobre os mais diversos mecanismos de opressão e de degradação humana nos diferentes processos de trabalho não é suficiente para a ação educativa. Precisa-se compreender a realidade para transformála, não simplesmente interpretá-la.

Hoje, o ProfEPT configura um espaço privilegiado de constituição do humano enquanto fim e não meio como normalmente o capital compreende. A soma dos mais de 800 mestrandos do Programa, de 200 professores nos 36 polos, de 30 mil candidatos, participantes do processo seletivo do ENA 2019, representam em si um movimento admirável, micro e macro, em busca de uma transformação social a partir do conhecimento. A leitura cuidadosa e o debate acadêmico sobre as bases conceituais da EPT retratam uma inovação, um salto qualitativo em direção aos novos processos de entendimento acerca de seu sentido enquanto Rede Federal.

O ProfEPT é uma poderosa oportunidade de representação da Rede Federal à luz de sua identidade e de seu ofício. Para que ele cumpra seu efetivo papel, precisa-se problematizar os paradigmas no campo da educação, do ensino, da ciência, da tecnologia e os sentidos dados ao trabalho docente e ao trabalho como princípio educativo. 


\section{REFERÊNCIAS}

AGUIAR, Luiz Edmundo Vargas de; PACHECO, Eliezer Moreira. Os Institutos Federais de Educação, Ciência e Tecnologia como política pública. In: ANJOS, Malyta Brandão dos; RÔSAS, Giselle. As políticas públicas e o papel social dos Institutos Federais de Educação, Ciência e Tecnologia. Natal: IFRN, 2017.

ANASTASIOU, Léa das Graças Camargo; ALVES, Leonir Pessate. Processos de ensinagem na universidade. Pressupostos para as estratégias de trabalho em aula. 3. ed. Joinville: Univille, 2007.

ANTUNES, Ricardo. Os sentidos do trabalho: ensaio sobre a qualificação e a negação do trabalho. São Paulo: Boitempo, 1999.

ARENDT, Hannah. A Condição Humana. Rio de Janeiro: Civilização Brasileira, 2005.

ASSMANN, Hugo. Reencantar a Educação. Rio de Janeiro: Editora Vozes, 1998.

BACON, Francis. Novum Organum ou Verdadeiras Indicações acerca da Interpretação da Natureza. São Paulo: Abril Cultural, 1973.

BARROS, Elionora Cavalcanti de; VALENTIM, Márcia Cristina; MELO, Maria Amélia Aragão. O debate sobre o mestrado profissional na Capes: trajetória e definições. Revista Brasileira de Pós-Graduação (RBPG). Brasília, 2005; 2:124-38.

BRASIL. Resolução do Conselho Superior $n^{\circ}$ 161, de 16 de setembro de 2016. Criar o Programa de Pós-Graduação em Educação Profissional e Tecnológica e Aprovar sem Regulamento Interno. Disponível em < http://profept.ifes.edu.br/images/stories/ProfEPT/Turma2017/ Acesso em: 27 maio 2018.

BURGUETE, Maria da Conceição. História e Filosofia das Ciências. Lisboa: Instituto Piaget, 2004.

CHALMERS, Alan. A Fabricação da Ciência. São Paulo: UNESP, 1994.

CHALMERS, Alan. O que é ciência, afinal? São Paulo: Brasiliense, 1995.

CHEVALLARD, Yves. La transposición didáctica: del saber sabio al saber enseñado. Buenos Aires: Aique, 1991.

COMTE, Auguste. Cours de philosophie positive. Première et deuxième leçons. Une édition électronique réalisée à partir du livre d'Auguste Comte, Cours de philosophie positive (1830-1842). Paris: Librairie Larousse, 1936. 
DESCARTES, René. Discurso do Método. Descartes - Vida e Obra, Rio de Janeiro: Nova Cultural, 1996.

FREIRE, Paulo. Pedagogia do oprimido. Rio de Janeiro: Paz e Terra, 1987.

FREIRE, Paulo. Pedagogia da autonomia: saberes necessários à prática educativa. São Paulo: Paz e Terra, 2002.

FRIGOTTO, Gaudêncio; CIAVATTA, Maria; RAMOS, Marise (orgs.). Ensino médio integrado: concepção e contradições. São Paulo: Cortez, 2005.

FRIGOTTO, Gaudêncio. A polissemia da categoria trabalho e a batalha das ideias nas sociedades de classe. Revista Brasileira de Educação. Rio de Janeiro, v. 14, n. 40, p. 168-194, jan./abr. 2009.

GRAMSCI, Antonio. Concepção dialética da história. Rio de Janeiro: Civilização Brasileira, 1978.

GRAMSCI, Antonio. Cadernos do cárcere. V. 1: Introdução ao estudo da filosofia. A filosofia de Benedetto Croce. Rio de Janeiro: Civilização Brasileira, 1999.

HEGEL, Georg Wilhelm Friedrich. Fenomenologia do Espírito. Abril, Col. Os Pensadores, XXX, 1974,

KUHN, Thomas. A estrutura das revoluções científicas. 3 ed. São Paulo: Perspectiva, 2000.

MARX, Karl. O capital. 7. ed. São Paulo: Difel, 1982.

MOLL, Jaqueline. Educação profissional e tecnológica no Brasil contemporâneo: desafios, tensões e possibilidades. Porto Alegre: Artmed, 2010.

MORIN, Edgar; FREITAS, Lima de; NICOLESCU, Basarab. Carta da Transdisciplinaridade. Portugal, Convento da Arrábida, 6 de novembro de 1994.

MORIN, Edgar. Os sete saberes necessários à educação do futuro. 12 ed. São Paulo: Cortez; Brasília: DF: UNESCO, 2007a.

MORIN, Edgar. Introdução ao pensamento complexo. 3. ed. Porto Alegre: Sulina, 2007b.

MORIN, Edgar. Ciência Com Consciência. São Paulo: Bertrand Brasil, 2014. 
MOURA, Dante Henrique. Trabalho e Formação Docente na Educação Profissional. 1 Ed. Coleção Formação Pedagógica, V. III. Curitiba: IFPR/EAD, 2014.

NÓVOA, António Sampaio da. Profissão professor: Existe futuro para essa profissão? Congresso Internacional de Educação. Universidade do Vale do Rio dos Sinos. Salão de Atos. São Leopoldo, RS, 2011.

OLIVEIRA, Francisco de. Crítica à razão dualista/ 0 ornitorrinco. São Paulo: Boitempo, 2003.

OLIVEIRA, Francisco de; RIZEK, Cibele Saliba. (orgs.). A era da indeterminação. São Paulo: Boitempo, 2007, p. 15-45.

POPPER, Karl. A lógica da pesquisa Científica. São Paulo: Editora Cultrix, 1972.

SANTOS, Boaventura de Souza. Um discurso sobre as ciências 5. ed. São Paulo: Cortez, 2008.

SAVIANI, Demerval. Sobre a concepção de politecnia. Rio de Janeiro: Fiocruz, 1989.

SAVIANI, Demerval. Trabalho e educação: fundamentos ontológicos e históricos. Revista Brasileira de Educação. Rio de Janeiro. v. 12, n. 34, p. 152-180, jan./abr. 2007.

TARDIF, Maurice. Saberes docentes e formação profissional. 2. ed. Petrópolis: Vozes, 2002. 